\title{
Resistive Switching in Stabilized Zirconia Films Studied by Conductive Atomic Force Microscopy
}

\author{
Dmitry Filatov, Dmitry Antonov, Ivan Antonov, Alexander Kasatkin, Oleg Gorshkov \\ Research and Educational Center for Physics of Solid State Nanostructures, Lobachevsky State University of Nizhny Novgorod, \\ Nizhny Novgorod, Russia \\ Email:dmitry_filatov@inbox.ru
}

How to cite this paper: Filatov, D., Antonov, D., Antonov, I., Kasatkin, A. and Gorshkov, O. (2017) Resistive Switching in Stabilized Zirconia Films Studied by Conductive Atomic Force Microscopy. Journal of Materials Science and Chemical Engineering, 5, 8-14.

http://dx.doi.org/10.4236/msce.2017.51002

Received: September 27, 2016

Accepted: January 1, 2017

Published: January 4, 2017

\begin{abstract}
We have applied Conductive Atomic Force Microscopy (CAFM) to study the microscopic mechanism of resistive switching in the ultrathin $(3-5 \mathrm{~nm})$ yttria stabilized zirconia (YSZ) films. Using CAFM, we were able to trace the growth of the individual conductive filaments, which are considered now to be responsible for the resistive switching effect in the transition metal oxides. The growth of the filaments has been proven to be initiated by the defects in the film material including the ones, which are the concentrators of the electric field, in particular, by the roughness (hillocks) of the film/substrate interface. The electron transport via individual filaments has been studied. Besides the butterfly-type hysteresis in the current-voltage $(I-V)$ curves of the probeto-sample contact typical for the bipolar resistive switching, we have observed the $I$ - $V$ curves with resonant peaks attributed to the resonant electron tunneling via the localized electron states in the filaments.
\end{abstract}

\section{Keywords}

Resistive Switching, Yttria Stabilized Zirconia, Conductive Atomic Force Microscopy

\section{Introduction}

Resistive switching (RS) was studied extensively in the last decade due to the prospects of its application in novel non-volatile memory (Resistive Random Access Memory, RRAM) [1]. The effect of RS consists in a reversible change of the resistance of a thin dielectric film sandwiched between two conductive electrodes under the electric voltage applied between the electrodes. Today's understanding of the RS mechanism in the transition metal oxides is based on a con- 
cept of the motion of the oxygen vacancies $\left(\mathrm{V}_{\mathrm{O}} \mathrm{s}\right)$ in the electric field between the electrodes [2]. The $\mathrm{V}_{\mathrm{O}}$ s form the conductive filaments growing through almost whole insulator layer (the forming process) and, thus, shortcut the electrodes. When the reverse bias is applied, the filaments are destroyed at one of electrodes, and the resistance of the dielectric is restored (the bipolar RS mechanism) [3].

It is clear from the above, that the availability and mobility of the $\mathrm{V}_{\mathrm{O}}$ s are essential for the RS in the transition metal oxides. In this scope, yttria stabilized zirconia (YSZ) $\mathrm{ZrO}_{2}\left(\mathrm{Y}\right.$ ) is very promising for RRAM applications since the $\mathrm{V}_{\mathrm{O}}$ concentration in $\mathrm{YSZ}$ is equal to $1 / 2$ that of $\mathrm{Y}$, and can be controlled precisely by varying Y molar fraction [4]. Although a lot of work was devoted to studying RS, many details of the RS mechanism in oxides are not clarified completely yet [5], including the processes at the metal-dielectric interfaces, particularly, the electric-field induced transition of $\mathrm{O}^{2-}$ ions from the dielectric into the metal electrode and back [6]. For deeper understanding of the microscopic details of RS mechanism, the appropriate experimental techniques are needed. Conductive Atomic Force Microscopy (CAFM) has been proven to be a powerful tool for studying RS at the nanometer scale [7]. Today, the development of RRAM meets the scaling problem: the RS mechanisms in the RRAM cells with the micrometers size electrodes appear to differ from these in the ones of less size [8]. From this viewpoint, CAFM is a good model system for studying the RS mechanisms in the nanometer-sized devices since the size of the probe-to-sample contact $(<10 \mathrm{~nm})$ is of the same order of magnitude as the expected size of electrodes in future RRAM devices [9]. For instance, CAFM allows studying the electron transport via individual filaments [10].

The purpose of the present study was to investigate the microscopic details of the RS mechanisms in the YSZ films using CAFM.

\section{Experimental}

The YSZ films with the thickness $d=3-5 \mathrm{~nm}$ were deposited onto $n^{+}-\mathrm{Si}(100)$ substrates covered by $\approx 2 \mathrm{~nm}$ thick native oxide $\mathrm{SiO}_{2}$ at $300^{\circ} \mathrm{C}$ by Magnetron Sputtering in $\mathrm{Ar}-\mathrm{O}_{2}$ gas mixture (50/50\% mol.) from mixed $\mathrm{ZrO}_{2}-\mathrm{Y}_{2} \mathrm{O}_{3}$ powder targets. The molar fraction of $\mathrm{Y}_{2} \mathrm{O}_{3}$ in the target material was $0.12 \pm 0.01$. In some cases, the YSZ films were deposited onto $\mathrm{Au}(40 \mathrm{~nm}) / \mathrm{Cr}(10 \mathrm{~nm})$ stacks on the $\mathrm{SiO}_{2} / \mathrm{Si}(100)$ substrates. Some samples were annealed in Ultra High Vacuum (UHV) at 300 and $500^{\circ} \mathrm{C}$ for 1 hour.

The CAFM investigations were carried out in UHV at $300 \mathrm{~K}$ using Omicron ${ }^{\circledR}$ UHV AFM/STM LF1 installed into Omicron ${ }^{\circledR}$ MultiProbe ${ }^{\mathrm{TM}}$ RM UHV system. The base pressure inside the UHV chamber was $\sim 10^{-10}$ Torr. NT MDT ${ }^{\circledR}$ NSG-11 CAFM probes with diamond like coating (DLC) and the tip curvature radius $R_{p} \approx 70 \mathrm{~nm}$ were used.

RS was studied by recording the cyclic current voltage $(I-V)$ curves of the probe-to-sample contact: the voltage between the probe and the sample $V_{g}$ was swept from $V_{\min }$ to $V_{\max }\left(V_{\min }<V_{\text {reset }}\right.$ and $V_{\max }>V_{\text {set }}$, where $V_{\text {set }}$ is the threshold voltage for switching from "OFF" state to "ON" one and $V_{\text {reset }}$ is the threshold 
for switching back to "OFF" state) and back from $V_{\max }$ to $V_{\min }$. In another mode, a selected area on the sample surface was scanned in Contact Mode with $V_{\mathrm{g}}>$ $V_{\text {set }}$ in order to switch the oxide film within this area into "ON" state. In order to switch the film material back into "OFF" state, the respective area was scanned again at $V_{\mathrm{g}}<V_{\text {reset. }}$ The results of switching was examined by acquiring the CAFM (or current) image $I_{\mathrm{t}}(x, y)$ where $I_{\mathrm{t}}$ is the probe current and $x, y$ are the probe coordinates on the sample surface at $\left|V_{\mathrm{g}}\right|<V_{\text {set, }}, V_{\text {reset. }}$.

\section{Results and Discussion}

Figure 1(a) shows typical $I-V$ curve of a CAFM probe contact to YSZ (3 $\mathrm{nm}) / \mathrm{SiO}_{2} / \mathrm{Si}$ film surface. A well expressed hysteresis typical for the bipolar RS was observed. Note that the estimate of the electric field strength in the YSZ film material $F \sim V \max / d$ for $V_{\max }=5 \mathrm{~V}$ and $d=5 \mathrm{~nm}$ makes $\sim 10^{7} \mathrm{~V} / \mathrm{cm}$. This value is close to the breakdown voltage in YSZ [4] and is well enough to initiate the forming process.

Figure 1(b) shows a CAFM image of an $\mathrm{YSZ}(3 \mathrm{~nm}) / \mathrm{SiO}_{2} / \mathrm{Si}$ film annealed in $\mathrm{UHV}$ at $500^{\circ} \mathrm{C}$. The image in Figure $1(\mathrm{~b})$ was acquired at $V_{\mathrm{g}}=-6 \mathrm{~V}$ (in Omicron ${ }^{\circledR} \mathrm{UHV}$ AFM/STM LF1, $V_{g}$ is applied to the sample relative to the probe). Note that $\left|V_{\mathrm{g}}\right|>V_{\text {set }} \approx 5 \mathrm{~V}$, as follows from Figure 1(a). The spots of increased probe current $I_{\mathrm{t}}$ (hereafter called current channels) were observed in the CAFM image. These spots were attributed to the electric current flowing through the individual filaments formed in the course of scanning under the electric field between the AFM probe and $n^{+}$-Si substrate. The sizes of the current channels $(\sim 100 \mathrm{~nm})$ are consistent with the values of $R_{\mathrm{p}}(\approx 70 \mathrm{~nm})$. Earlier, we have shown the sizes of the current images of the localized electron states inside the tunnel transparent dielectric films (metal nanoclusters, MNCs, point detects, etc.) to be determined by the size and shape of the probe-to-sample contact area and not to depend on the defect size [11]. The same should hold for the case of imaging the filaments. However, the current channels in Figure 1(b) had a half-moon shape while the AFM probe tips were round generally. To explain this disagreement, one must take into account the filaments to grow during scanning. Initially the
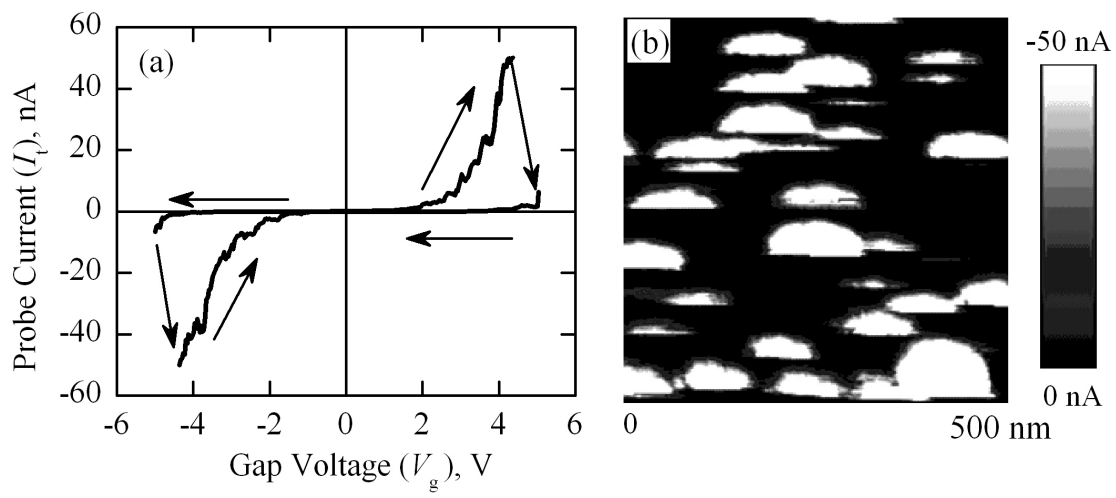

Figure 1. (a) Typical $I-V$ curve of CAFM probe contact to an $\mathrm{YSZ}(3 \mathrm{~nm}) / \mathrm{SiO}_{2} / \mathrm{Si}$ film annealed in UHV at 500C for 1 hour; (b) CAFM image of the same film recorded at $V_{\mathrm{g}}=$ $-6 \mathrm{~V}$. 
film was not tunnel-transparent. Once a filament grows through the film, $I_{t}$ increases. So far, in Figure 1(b) one can see the current images of the rest of AFM probe imaged by the emerged filaments. It is worth noting that the surface density of the current channels increased after the second scanning the same area that supports the above suggestion on forming new filaments while scanning.

Most likely, the filaments form preferentially in the points, where some defects are located inside the film. These defects concentrate the electric field between the probe and the sample promoting the filament growth. In order to confirm the above hypothesis, we have studied the YSZ films deposited onto Au (40 $\mathrm{nm}) / \mathrm{Cr}(10 \mathrm{~nm})$ sublayers on the $\mathrm{SiO}_{2} / \mathrm{Si}$ substrates. Figure 2(a) shows an AFM image of an $\mathrm{Au} / \mathrm{Cr} / \mathrm{SiO}_{2} / \mathrm{Si}$ sublayer. The $\mathrm{Au}$ surface had an islanded structure typical for the thin Au films deposited in vacuum.

Figure 2(b) shows a CAFM image of the YSZ film deposited onto the $\mathrm{Au} / \mathrm{Cr} /$ $\mathrm{SiO}_{2} / \mathrm{Si}$ stack and annealed in UHV at $300^{\circ} \mathrm{C}$ for 1 hour. A square area of 1.5 by $1.5 \mu \mathrm{m}^{2}$ in size (in the middle of the CAFM frame) was modified by scanning this area two times at $V_{\mathrm{g}}=-2 \mathrm{~V}$. A fair correlation between the Au surface morphology in Figure 2(a) and the CAFM image in Figure 2(b) indicate the Au grains to promote the filament forming. Earlier, promotion of the filament growth by the substrate roughness was reported in [12] [13]. The authors of the cited works suggested the hillocks on the substrate to act as the electric field concentrators stimulating the nucleation of filaments as shown in Figure 2(c). The results of the present study confirm the suggestions in the early works by direct experimental observations at nanometer scale.

Note that scanning the $\mathrm{YSZ} / \mathrm{Au} / \mathrm{Cr} / \mathrm{SiO}_{2} / \mathrm{Si}$ film at $V_{\mathrm{g}}=-2 \mathrm{~V}$ appeared to be enough to switch the film into "ON" state whereas $V_{\text {set }}$ was at least 2.5 times higher for the $\mathrm{YSZ} / \mathrm{SiO}_{2} / \mathrm{Si}$ film (cf. Figure 1). It is not surprising since in the latter case a considerable fraction of $V_{g}$ drops on the $\mathrm{SiO}_{2}$ layer as well as on the depletion layer at the $\mathrm{SiO}_{2} / \mathrm{Si}$ interface biased reversely. In contrary, in the case when the YSZ films are deposited onto the $\mathrm{Au} / \mathrm{Cr} / \mathrm{SiO}_{2} / \mathrm{Si}$ stack, the whole voltage $V_{\mathrm{g}}$ drops on the YSZ film. As a result, the electric field in the oxide appears to be stronger at equal $V_{\mathrm{g}}$ in the former case. The impact of the surface roughness enhances this effect even more.

It is worth noting that no current channels were observed on the $\mathrm{YSZ} / \mathrm{SiO}_{2} / \mathrm{Si}$
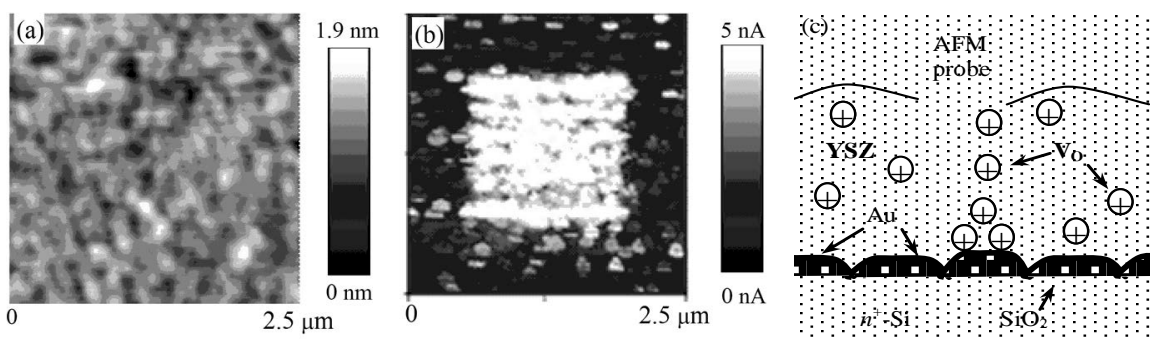

Figure 2. (a) AFM image of $\mathrm{Au}(40 \mathrm{~nm}) / \mathrm{Cr}(10 \mathrm{~nm}) / \mathrm{SiO}_{2} / \mathrm{Si}$ stack; (b) CAFM image (recorded at $\mathrm{V}_{\mathrm{g}}=2 \mathrm{~V}$ ) of a $4 \mathrm{~nm}$ thick YSZ film deposited onto an $\mathrm{Au} / \mathrm{Cr} / \mathrm{SiO}_{2} / \mathrm{Si}$ stack and annealed in $\mathrm{UHV}$ at $300^{\circ} \mathrm{C}$ for 1 hour. The square area 1.5 by $1.5 \mu \mathrm{m}^{2}$ in the millde was modified by scanning 2 times at $\mathrm{V}_{\mathrm{g}}=-2 \mathrm{~V}$; (c) Schematic of a filament growth stimulated by an $\mathrm{Au}$ island on the substrate. 
films annealed at $300^{\circ} \mathrm{C}$. As the $\mathrm{V}_{\mathrm{O}}$ concentration in YSZ is determined by $\mathrm{Y}$ molar fraction [4] (as it has been already mentioned above), it could be hardy affected by annealing. So far, the role of annealing could be limited to promoting the diffusion of $\mathrm{O}^{2-}$ ions to the YSZ film surface followed by the yield of oxygen out of the film into UHV. The residual excess $\mathrm{Zr}$ atoms may coagulate into the $\mathrm{Zr}$ MNCs [14]. These Zr MNCs formed inside the YSZ film during annealing in $\mathrm{UHV}$ are most likely the defects promoting the filament growth in the $\mathrm{YSZ} / \mathrm{SiO}_{2} /$ Si samples.

Besides the butterfly-type hysteresis loops in the $I$ - $V$ curves typical for the bipolar RS like in Figure 1(a), we have also observed the $I$ - $V$ curves with peaks (Figure 3). Earlier, we have observed the peaks in the $I$ - $V$ curves from thin dielectric films with MNCs and attributed these peaks to the resonant tunneling of electrons between the AFM probe and the substrate through the quantum confined energy states in small $(\sim 1 \mathrm{~nm})$ MNCs [15].

In the samples studied in the present work, the peaks in the $I$ - $V$ curves can be attributed to the resonant electron tunneling via the discrete energy levels of some localized electronic states inside the filaments. These localized electronic states with quantized energy spectrum could be related to small enough $(\sim 1 \mathrm{~nm}$ in size) Zr MNCs emerged during annealing in UHV due to the yield of oxygen into vacuum (as it has been already discussed above).

On the other hand, such localized electronic states may originate from a $V_{O}$ (or several ones) separated from the other parts of a filament by the vacancies filled by $\mathrm{O}^{2-}$ ions as shown in Figure 2(c). Earlier, the authors of [16] had considered $\mathrm{V}_{\mathrm{O}}$ filled an $\mathrm{O}^{2-}$ ion in a vacancy chain (filament) as a quantum point contact (QPC); the effects typical to QPSs, e. g. conductance quantization have been observed experimentally. Here, we postulate multiple QPCs model to explain the resonant features in the $I-V$ curves of the filaments.

Another possible candidate for such a localized state could be an $\mathrm{Y}^{3+}$ ion inside a filament. Among various types of $I$ - $V$ curves, we have observed the ones with multiple equidistant peaks, as shown in Figure 3(b). Such features are typical to the tunneling through so called "colored" atom [17], and could be attributed to the tunneling via the electron states in $4 f$ shell of $\mathrm{Y}^{3+}$ ion in $\mathrm{ZrO}_{2}$ lattice.
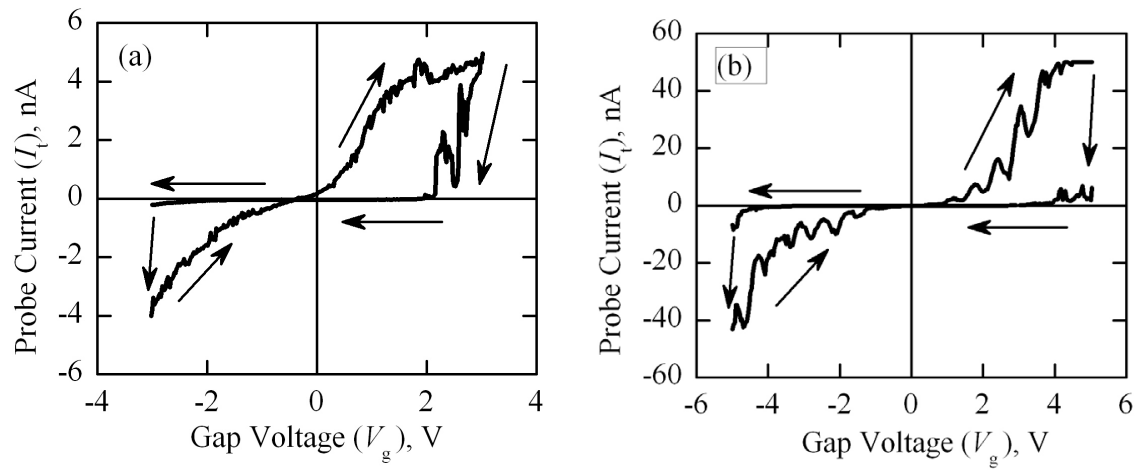

Figure 3. The examples of $I$ - $V$ curves of the AFM probe contact to the $\mathrm{YSZ}(4 \mathrm{~nm}) / \mathrm{Au} /$ $\mathrm{Cr} / \mathrm{SiO}_{2} / \mathrm{Si}$ film (a) and to $\mathrm{YSZ}(5 \mathrm{~nm}) / \mathrm{SiO}_{2} / \mathrm{Si}$ (b) one. 


\section{Conclusion}

The results of present study demonstrate CAFM to be a powerful method for studying the microscopic mechanisms of resistive switching in the ultrathin transition metal oxide films at the nanometer scale. Particularly, applying CAFM allowed us real time tracing the filament growth, associating the filament nucleation with the substrate roughness, and studying the electron transport via individual filaments. The nonlinear features observed in the $I-V$ curves were attributed to the resonant electron tunneling via the localized electronic states in the filaments related to the $\mathrm{Zr}$ nanoclusters or to the $\mathrm{Y}$ atoms.

\section{Acknowledgements}

The present study was supported by Ministry of Education and Science, Russian Federation (Project No. 3.2441.2014/K).

\section{References}

[1] Jeong, D.S., et al. (2012) Emerging Memories: Resistive Switching Mechanisms and Current Status. Rep. Prog. Phys., 75, Article ID: 076502. https://doi.org/10.1088/0034-4885/75/7/076502

[2] Lee, J.S., Lee, S. and Noh, T.W. (2016) Resistive Switching Phenomena: A Review of Statistical Physics Approaches. Appl. Phys. Rev., 2, Article ID: 031303.

[3] Marchewka, A., et al. (2015) Nanoionic Resistive Switching Memories: on the Physical Nature of the Dynamic Reset Process. Adv. Electron. Mater., 2, Article ID: 1500233.

[4] Abbas, H.A. (2012) Stabilized Zirconia for Solid Oxide Fuel Cells or Oxygen Sensors: Characterization of Structural and Electrical Properties of Zirconia Doped with Some Oxides. LAP Lambert Academic.

[5] Kim, W., et al. (2016) Impact of Oxygen Exchange Reaction at the Ohmic Interface in $\mathrm{Ta}_{2} \mathrm{O}_{5}$-Based ReRAM Devices. Nanoscale. https://doi.org/10.1039/c6nr03810g

[6] Skaja, K., et al. (2015) Avalanche-Discharge-Induced Electrical Forming in Tantalum Oxide-Based Metal-Insulator-Metal Structures. Adv. Funct. Mater., 25, 71547162. https://doi.org/10.1002/adfm.201502767

[7] Lanza, M. (2014) A Review on Resistive Switching in High-k Dielectrics: A Nanoscale Point of View Using Conductive Atomic Force Microscope. Mater., 7, 21552182. https://doi.org/10.3390/ma7032155

[8] Menzel, S., Böttger, U., Wimmer, M. and Salinga, M. (2015) Physics of the Switching Kinetics in Resistive Memories. Adv. Funct.Mater., 25, 6306-6325. https://doi.org/10.1002/adfm.201500825

[9] Wong, H.-S.P., et al. (2012) Metal-Oxide RRAM. Proc. IEEE, 100, 1951-1970. https://doi.org/10.1109/JPROC.2012.2190369

[10] Rogala, M., et al. (2015) Resistive Switching of a Quasi-Homogeneous Distribution of Filaments Generated at Heat-Treated $\mathrm{TiO}_{2}(110)$-Surfaces. Adv. Funct. Mater., 25, 6382-6389. https://doi.org/10.1002/adfm.201500855

[11] Lapshina, M.A., Filatov, D.O. and Antonov, D.A. (2008) Current Image Formation in Combined STM/AFM of Metal Nanoclusters in Dielectric Films. J. Surf. Investigations: X-Ray, Synchrotron, and Neutron Techn., 2, 616-619. https://doi.org/10.1134/S1027451008040228 
[12] Lee, D.-Y., Wang, S.-Y. and Tseng T.-Y. (2010) Ti-Induced Recovery Phenomenon of Resistive Switching in $\mathrm{ZrO}_{2}$ Thin Films. J. Electrochem. Soc., 157, G166-G169. https://doi.org/10.1149/1.3428462

[13] Jeong, H.Y., Lee, J.Y. and Choi S.-Y. (2010) Direct Observation of Microscopic Change Induced by Oxygen Vacancy Drift in Amorphous $\mathrm{TiO}_{2}$ Thin Films. Appl. Phys. Lett., 97, Article ID: 042109. https://doi.org/10.1063/1.3467854

[14] Gorshkov, O.N., et al. (2012) Peculiarities in the Formation of Gold Nanoparticles by Ion Implantation in Stabilized Zirconia. Tech. Phys. Lett., 38, 185-187. https://doi.org/10.1134/S1063785012020253

[15] Filatov, D.O., et al. (2010) Resonant Tunneling through Individual Au Nanoclusters Embedded in Ultrathin $\mathrm{SiO}_{2}$ Films Studied by Tunneling AFM. J. Phys.: Conf. Series, 245, Article ID: 012018.

[16] Lian, X., et al. (2014) Multi-Scale Quantum Point Contact Model for Filamentary Conduction in Resistive Random Access Memories Devices. J. Appl. Phys., 115, Article ID: 244507. https://doi.org/10.1063/1.4885419

[17] Binnig, G. and Rohrer, H. (199) In Touch with Atoms. Rev. Mod. Pyis., 74, S324S330.

\section{Scientific Research Publishing}

Submit or recommend next manuscript to SCIRP and we will provide best service for you:

Accepting pre-submission inquiries through Email, Facebook, LinkedIn, Twitter, etc. A wide selection of journals (inclusive of 9 subjects, more than 200 journals) Providing 24-hour high-quality service User-friendly online submission system Fair and swift peer-review system Efficient typesetting and proofreading procedure Display of the result of downloads and visits, as well as the number of cited articles Maximum dissemination of your research work

Submit your manuscript at: http://papersubmission.scirp.org/ Or contact msce@scirp.org 